\title{
Exploring the Role of Dynamic Assessment in Language Education: An Introduction to the Special Issue
}

\author{
Próspero N. García
}

This special issue, 'Exploring the Role of Dynamic Assessment in Language Education', began to take shape at a colloquium of the same name at the 2016 Georgetown University Roundtable (GURT). That particular edition of GURT was organized by the Assessment and Evaluation Language Resource Center (AELRC) at Georgetown and was aptly titled Useful Assessment and Evaluation in Language Education. The purpose of our colloquium was to present and compare four novel approaches to Dynamic Assessment (DA) that would provide a richer understanding of how DA for L2 development had evolved over the years. Indeed, dynamic assessment, one of the main applications of Vygotsky's (1987) notion of Zone of Proximal Development (ZPD) applied to the teaching-learning-assessment dialectic, has been increasingly regarded as a fundamental construct in L2 education (Lantolf and Poehner, 2014). Framed within a Vygotskian sociocultural perspective, DA integrates instruction and assessment with the goal of ascertaining and promoting L2 development, placing the learner at the center of the teaching/learning activity. This is precisely one of the key elements of useful approaches to assessment and evaluation, 'a comprehensive approach to education that is accountable to the needs of learners, the values of scholarly disciplines, and the well-being of society' (Davis, 2018: vii). That is, rather than focusing on placement, diagnostic, achievement or other accountability measures, useful methods of assessment are transformative approaches that intend to provide a better understanding

\section{$\overline{\text { Affiliation }}$}

Rutgers University, Camden, NJ, USA. email:pg289@camden.rutgers.edu 
of the evaluation processes that occur in L2 education, with the goal of supporting and improving it (Davis, 2018: vii).

In this sense, DA is considered by many to be a form of transformative pedagogical activity where learning and assessment are not seen as two different processes, but as 'two sides of the same coin' (Lantolf and Poehner, 2011: 46). DA aims to identify learners' individual differences and needs in order to foster their linguistic development while they are being assessed. This is accomplished by offering mediation targeted at the learners' ZPD, understood here as 'the distance between the actual developmental level as determined by independent problem solving and the level of potential development as determined through problem solving under adult guidance or in collaboration with more capable peers' (Vygotsky, 1978: 86, italics in original). While the notion of ZPD has had many interpretations over the years (see Chaiklin, 2003: 44-45), it is essential to understand that the ZPD is not an ability, nor is it measured in terms of size (i.e. bigger vs. smaller ZPD). Rather, it is a metaphor that intends to capture what transpires when human beings engage in activity to socially construct meaning - either individually (I-me collaboration) or with others (me-world) - and foster development. Hence, in DA, ZPD activity can serve as a learning-development individual threshold indicator to point out where the teaching-learning process should be focusing its efforts in order to facilitate learner development.

This special issue frames DA theoretically, and provides four innovative approaches to its implementation in several different L2 instructional contexts, illustrated here by representative research and practice across multiple educational settings, languages, and activities.

In their article, Infante and Poehner investigate the use of DA as tooland-result activity in an ESL writing context, suggesting a shift in the assessment process - from being administered to learners to being undertaken by them. The authors argue that, while DA focuses on diagnosing learners' emerging abilities without losing sight of their development through instruction, Mediated Development (MD), seen as a dynamic process of joint thinking where mediator and learner engage in instructional tasks as dialectical activity, shows that it is necessary to include an assessment of the learner during instruction. This hypothesis is supported by the interactions that emerged during the implementation of MD, which fostered the learner's ability to create alternative meanings in her L2 writing. Their analysis suggests that DA and MD - as ZPD activity - can be implemented together to generate a more coherent and systematic L2 pedagogy anchored in sociocultural principles.

García's contribution on teacher cognition explores how an interactionist model of DA can be implemented as a tool for diagnosing and promoting

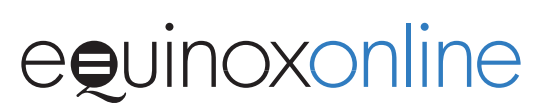


L2 teachers' microgenetic conceptual development and pedagogical beliefs. Through the analysis of a case-study of an experienced in-service teacher of Spanish, García's findings support Davin's (2016) claim that metacognitive mediation presented through DA is essential to aid learners in developing semiotic tools of self-regulation to promote their understanding and use of L2 concepts. This hypothesis is supported by the L2 teacher's increased levels of accuracy during mediated performance, her ability to conceptualize grammatical concepts, and the reshaping of her existing pedagogical and linguistic beliefs. The evidence presented in the article suggests that the model can be an effective tool to support in-service teachers' pedagogical content knowledge as well as their L2 conceptual development.

Zhang and Lu's article reports the application of a computerized DA (C-DA) to listening and reading comprehension in an intermediate-level Chinese classroom. Through the implementation of C-DA the authors were able to diagnose students' fully-developed and emerging abilities by offering graduated mediation during the activity and tracking the number of prompts needed in order to solve the tasks. Results from the diagnostic C-DA were used to place learners in three different groups according to their listening abilities and learning needs which enabled instructors to provide support that was more attuned to their ZPD. Based on the evidence provided by diagnostic test reports, student interviews, and end-of-semester course evaluations, Zhang and $\mathrm{Lu}$ propose that the integration of mediated diagnostic language assessment and instruction, not only assists in predicting students' learning potentials, but also supports individual differences by providing teachers with the tools to tailor instruction to students' actual needs, presenting a coherent and effective pedagogical model based on their ZPD.

Continuing with a whole-classroom approach to dynamic assessment, Davin and Gómez-Pereira examine the use of a sandwich approach to DA to track the development of number-modifier agreement in a sixth grade Spanish World Language classroom. More specifically, the authors explore how instructional interventions can be informed by this assessment, and the extent to which mediation can meet learner needs. Findings from their study show that by providing appropriate mediation during the DA sessions, learners were able to develop an understanding of agreement regardless of a problematic instructional design. Davin and Gómez-Pereira's work - along with García's and Infante and Poehner's in this special issue - support Davin's (2016) claim that both cognitive and metacognitive mediation are necessary to promote learners' conceptual development. These findings also contribute to a more informed sociocultural approach to L2 development by reiterating the need to generate a pedagogical sequence that provides learners with conceptual representations first, in order to mediate their understanding of how to

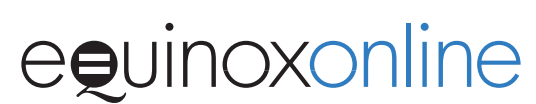


employ linguistic resources to make meaning, followed by a phase of interpersonal mediation (i.e. other-regulation) targeted to the learners' ZPD.

Antón's concluding commentary highlights the theoretical contributions and pedagogical implications of the investigations included in the special issue. She offers a state-of-the-art review of DA by summarizing its main principles and applications to L2 contexts in SLA research and practice. Her reflections, which underscore the field's general progress towards a consensus on improved research methods and quality in DA practice, also encourage further experimentation with the implementation of this instructional model, which should lead to a more comprehensive approach to language education based on sociocultural principles. Antón's article concludes with the common refrain found throughout this issue, one that highlights that the dialectical connection between theory and practice and instruction and assessment is at the center of DA.

Looking at the weight that notions such as mediation and ZPD activity have for a sociocultural understanding of what L2 assessment should do to promote L2 development opens an almost infinite array of research possibilities in the field of language education. While the articles included in the special issue address some of the processes as well as the outcomes of incorporating DA in L2 educational contexts, they represent only a small portion of the areas of investigation being developed from a sociocultural perspective. It is our hope that the insights provided by the authors will become a resource for researchers and practitioners alike, and that it will help inspire the pursuit of new areas of investigation to further the evolution of the field.

\section{Acknowledgments}

My sincere gratitude goes to Jim Lantolf for inviting me to guest-edit this special issue on Dynamic Assessment for Language and Sociocultural Theory, and for his feedback and constant support throughout its development. I also need to thank all the authors for all their work and wonderful contributions to this project, and our colloquium at GURT.

\section{References}

Chaiklin, S. (2003). The zone of proximal development in Vygotsky's analysis of learning and instruction. In A. Kozulin, B. Gindis, V. Ageyev, and S. Miller (Eds), Vygotsky's Educational Theory in Cultural Context, 39-64. Cambridge: Cambridge University Press. https://doi.org/10.1017/cbo9780511840975.004

Davin, K. J. (2016). Classroom dynamic assessment: A critical examination of constructs and practices. Modern Language Journal 100 (4): 813-829. https://doi.org/10.1111/modl .12352

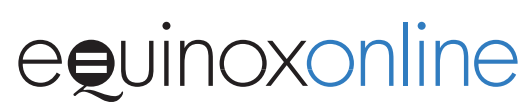


Davis, J. M. (2018). Preface. In J. M. Davis, J. M. Norris, M. E. Malone, T. H. McKay, and Y. Son (Eds), Useful Assessment and Evaluation in Language Education, vii-ix. Washington, DC: Georgetown University Press. https://doi.org/10.2307/j.ctvvngrg

Lantolf, J. P. and Poehner, M. E. (2011). Dynamic Assessment in the Foreign Language Classroom: A Teacher's Guide, 2nd edition. University Park, PA: CALPER.

Lantolf, J. P. and Poehner, M. E. (2014). Sociocultural Theory and the Pedagogical Imperative in L2 Education: Vygotskian Praxis and the Research /Practice Divide. New York: Routledge. https://doi.org/10.4324/9780203813850

Vygotsky, L. S. (1978). Mind in Society: The Development of Higher Psychological Processes. Cambridge, MA: Harvard University Press.

Vygotsky, L. S. (1987). Thinking and speech. In R. W. Rieber and A. S. Carton (Eds), The Collected Works of L. S. Vygotsky. Vol. 1. Problems of General Psychology, 39-285. New York: Plenum. https://doi.org/10.1017/s0142716400008341 